\section{The Elasticity of the Collagen Triple Helix}

R. Bowitz, R. Jonak, H. Nemetschek-Gansler, Th. Nemetschek and H. Riedl

Pathologisches Institut der Universität Heidelberg,

Abt. für Ultrastrukturforschung

\section{G. Rosenbaum}

Europäisches Laboratorium für Molekularbiologie, Heidelberg/Hamburg

The stress-strain diagram of native wet collagen fibers shows two linear parts which are separated by a sharp kink [1]. With the help of x-ray diffraction (Fig 1) and the use of a synchrotron $x$-ray source [2] we were able to demontrate the following:

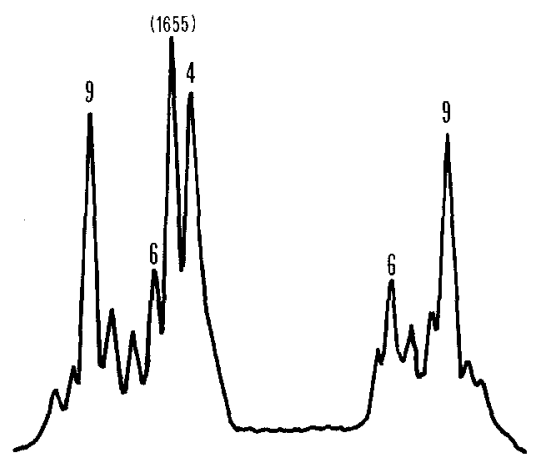

Fig. 1. Meridional $x$-ray reflections from a 22 month-old RTT fiber ( $\varnothing 0.09 \mathrm{~mm}^{2}$; strain $7 \%$ ). The spectrum was recorded by a positionsensitive detector with a xenon-methane mixture as chamber gas. Time of exposition $100 \mathrm{~s}$; max. peak height 1655 pulses. In order to exclude disturbing scattering a large zone around the primary beam was masked. The distance of the peaks of the 9th order comes to 395 channels. This being so, the resolution is approximately the width of one channel, and one can minimally detect a change of $0.25 \%$. The low-angle spacing amounts to $685 \pm 1 \AA$. After discharge it was reduced again to the starting value of $670 \AA$ lished elsewhere.
1. The $670-\AA$ low-angle spacing is due to secondary units which will not be influenced in the lower part (strain $<3 \%$ ), because

2. the intermolecular cross-links out of peptide chains will be elongated in such a way that the secondary units can slip reversibly [3].

3. In the upper linear part (strain $>3 \%$ ) the force is applied to the secondary units and now the triple helix itself becomes elongated elastically, so that the low-angle spacing increases reversibly by $2-3 \%$.

A detailed communication will be pub-

Prof. Dr. K.C. Holmes, MPI für Medizinische Forschung Heidelberg, danken wir für erwiesene Hilfsbereitschaft, ebenso A. Harmsen, EMBO Hamburg. Frau B. Moraw und Fräulein B. Höltken danken wir für ihre Mitarbeit. Mit Unterstützung der Deutschen Forschungsgemeinschaft (Schwerpunktprogramm: Biopolymere und Biomechanik von Bindegewebssystemen).

\section{Received September 23, 1976}

1. Bowitz, R., et al. : Naturwissenschaften 62 , 493 (1975)

2. Roscnbaum, G., Holmes, K.C., Witz, J.: Nature 230, 434 (1971)

3. Nemetschek, Th., Bowitz, R., NemetschekGansler, H.: Verh. Dtsch. Ges. Path. 59, 34 (1975)
(Fig. 1a). Cell bodies of the giant fibres are still undetected and it is therefore unclear whether the giant fibres represent single axons or belong to a train of nerve cells. Electron microscopy reveals a tiny glial sheath with extracellular collagenous material around the giant fibres which is often interrupted by small naked fibres or by the protrusions of the giant fibres making synaptic contacts.

Electrophysiology. The conduction of impulses along the ventral nerve cord was investigated by recording extracellular electrical responses after electrical or mechanical stimulation. A single electric shock applied to the nerve cord evokes multiphasic compound action potentials which are conducted in both directions along the cord. A short-latency large-amplitude component, which can appear as a simple triphasic or as a smaller multiphasic potential, is a characteristic feature of the response. These responses do not occur
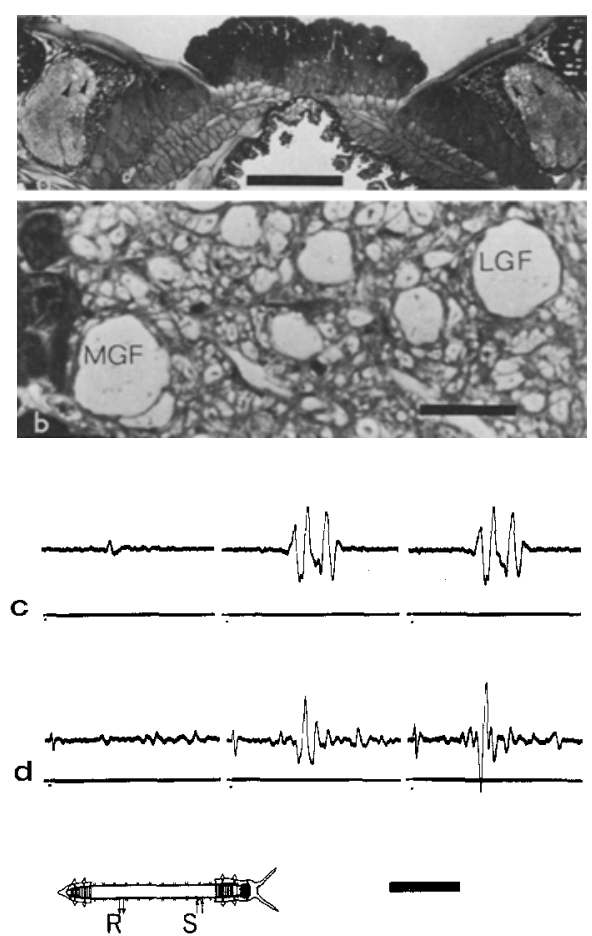

Fig. 1. Transverse section through ventral nerve cords and muscles of Peripatoides leuckarti. (a) Position of the giant fibres in widely separated nerve cords is marked by arrows. Scale $200 \mu \mathrm{m}$. (b) Medial (MGF) and lateral giant fibre (LGF). Scale $20 \mu \mathrm{m}$. (c, d) Recordings from ventral nerve cord after single electric shock. (c) Large compound potential remains unchanged when the stimulus intensity is increased. Asynchronous arrival of action potentials of two axons at recording site. (d) One axon activated initially (middle); large potential caused by simultaneous arrival from spikes of two axons (right) when stimulus intensity increased. Drawing shows nervous system, recording site $(R)$ and stimulus point $(S)$; time scale $20 \mathrm{~ms}$
* Present address: Zoologisches Institut der Universität Köln, Weyertal 119, 5 Köln 41, W.-Germany a polysegmental giant-fibre system in the ventral nerve cord of the Australian Onychophoran Peripatoides leuckarti. $20 \mu \mathrm{m}$ in diameter in animals more than $2 \mathrm{~cm}$ long) is found in the dorsal part of each nerve cord and can be traced along the segments up to the connectives of the brain in serial sections. One of these giant fibres lies adjacent to the medial pericaryal layer; the other is situated more laterally 